\title{
Artificial Neural Networks Driven Data-Based Optimization Analysis to Locate Crisis Reaction Offices for Marine Transportation in Antalya
}

\author{
Emre Demir ${ }^{a}$ and Caner Akar ${ }^{* *}$ \\ a Department of Civil Engineering, Faculty of Engineering and Natural Sciences, Antalya Bilim University \\ ${ }^{c}$ Construction Technologies, Vocational School, Antalya Bilim University \\ *E-mail address: caner.akar@antalya.edu.tr ${ }^{\mathrm{b} *}, \underline{\text { emredemir07@gmail.com }}^{\mathrm{a}}$
}

ORCID numbers of authors:

0000-0003-0013-4482, 0000-0003-0652-8423*

Received date: 01.12 .2021

Accepted date: 29.12 .2021

\begin{abstract}
A mishap might happen at any port along Antalya's 500-kilometer shorelines, and the counter spillage group ought to be on schedule for an intercession. The aim of this study is to decide the most appropriate areas for the counter spillage group office for Antalya's tourist ports. For this reason, Tree Seeds Algorithm (TSA), Symbiotic Organisms Search (SOS), Sooty Terns Optimization Algorithm (STOA), and Weiszfeld Algorithm (WA) optimization methods are used to track down the most advantageous area. The first three procedures are almost new and forward-thinking methods. Notwithstanding, the last one is a notable calculation for taking care of organization-based enhancement issues. This research aims to accomplish an ideal area and evaluate the exhibitions of TSA, SOS, STOA, and WA. Hence, this article offers a crisis reaction office area for oil leakage safety brought about by marine mishaps in Antalya Gulf. The originality and the main contribution of the paper to the literature is as follows: 1) for the first time, the presentations of the four optimization algorithms are analyzed and inspected together, 2) the most appropriate locations for the counter spillage group office for Antalya's ports are determined for first time in the literature.
\end{abstract}

Keywords: Transportation optimization, marine mishaps, location analysis, Antalya

\section{Introduction}

Marine mishaps jeopardize biological equilibrium and speed up the alteration in the wildlife at the waterfront regions antagonistically. Marine accidents or mishaps are a threat to ecological balance and tourism [1-3]. Natural habitat at the coastal areas is adversely affected due to chemical pollutions occurring near ports. The chemicals affect the environment, and the depletion of species makes fishery difficult or less economical [4-7]. Accidents or mishaps at sea put human life at risk, too. Accidents or mishaps at sea put human life at risk, too. When a spillage occurs in Antalya Gulf in Turkey, it is essential to limit its effect, so the mediation should be made as fast as expected. Antalya, a city in Turkey with almost 2,000,000 individuals living in seaside areas, has many ports utilized fundamentally for the commercial and transportation industry.

Antalya has almost two million residents and millions of tourists annually in twelve seaside districts $[8,9]$. Besides the residents and the tourists, Antalya's coasts are home to countless numbers of fish and other animals [10]. Therefore, a possible accident on Antalya's five- 
hundred-kilometer coastline should encounter with quick intervention. Thus, the location of an anti-leakage team for a quick response is essential. The team should be close to all the ports and closer to those with higher capacity. Ultimately, finding an optimum location of the bases for a quick-response team becomes an optimization problem. Moreover, the risk of an accident is equal to the likelihood of the accident multiplied by its severity [11]. It is assumed that the risk of an accident is proportional to the port's capacity (i.e. the more ships there are, the more accidents there may be). It is also assumed that severity of an accident is proportional to the distance of the anti-leakage team. The outcome of the accident may be less severe if the intervention is made quickly and vice versa. Thus, to present the main gist of this article, a sutiable location for a counter spillage group office for Antalya's ports is required because no area has been assigned recently for this purpose.

Furthermore, the paper's originality and the main contribution to the literature can be described as follows. Firstly, in this study, finding the optimum location for an emergency response facility is processed by four optimization techniques, which are Tree Seeds Algorithm (TSA), Symbiotic Organisms Search (SOS), Sooty Terns Optimization Algorithm (STOA), and Weiszfeld Algorithm (WA). TSA, SOS, and STOA are brand new techniques for continuous optimizations, and WA is an aged but widely used technique [12-15]. Such approaches were applied to several transportation engineering problems [16-21]. However, the presentations of the four optimization algorithms are analyzed and inspected together, and their performances are compared and discussed in this paper for the first time. Secondly, for the first time in the literature for Antalya's ports, the most suitable locations for a counter spillage group office are determined. The proposed location and its spatial characteristics are also evaluated and discussed in this study.

This paper is designed as follows. Section 2 provides the optimization problem. After Section 3 offers a succinct interpretation of the methodology proposed, results and discussion are delivered in Section 4. Lastly, Section 5 deduces the article.

\section{The Optimization Problem}

Regional ministries fund private companies in order to deal with marine accidents. The companies appoint quick-response teams to make a quick intervention in case of a possible accident near seaports. Supposedly, the possibility and severity of an emergency on a given port are proportional to the port's capacity and distance to the emergency facility, respectively. Hence, the objective of the problem is a function of the team's distance and ports' capacity. Therefore, the objective function can be formulated as in Eq. (1).

$$
Z_{\text {objective }}=\sum_{j=1}^{N_{\text {ports }}} d_{j} c_{j}
$$

Where; $N_{\text {ports }}$ denotes the number of ports that are in consideration, $c_{j}$ represents the capacity of the port $j$ and $d_{j}$ is the Euclidian distance between the base of the anti-leakage team and the port $j, Z_{\text {objective }}$ is the objective function which is to be minimized by optimization algorithms. Antalya's thirteen touristic ports are pointed out in "Fig. 1", and the bubble sizes represent the amount of the capacities. 


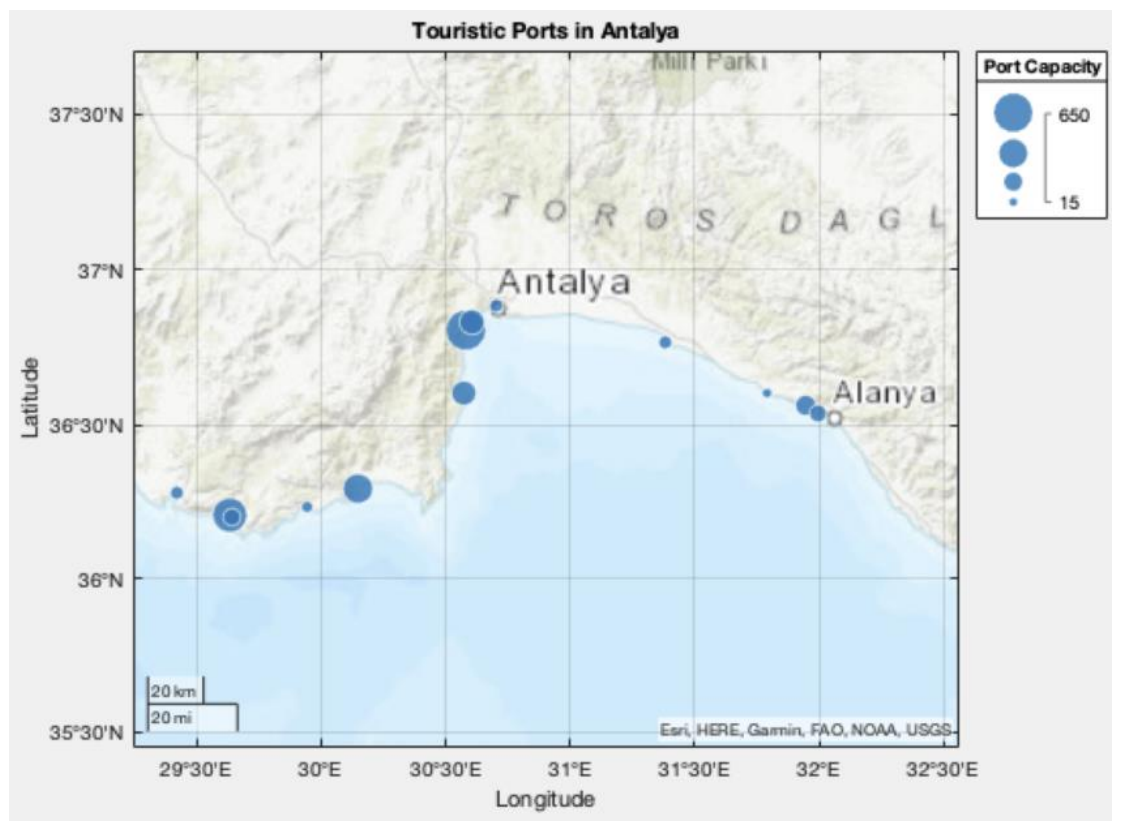

Fig. 1. Antalya's Touristic Ports

In this paper, only the touristic ports are taken into consideration. Trading ports are ignored since the shipment intensity of a trade port is not calculated according to its capacity. Like the trading ports, archeological ports are also ignored because there is no precise data about their anchoring capacity.

In this problem, the location of the marine facility can be anywhere on Antalya's coastline. Therefore, Antalya's coastline coordinates are extracted from GSHHS (A Global Selfconsistent, Hierarchical, High-resolution Geography Database [22]). The coordinate data includes latitudes and longitudes of the coastline. "Fig. 2" shows the coast's GSHHS data and its approximate continuous function.

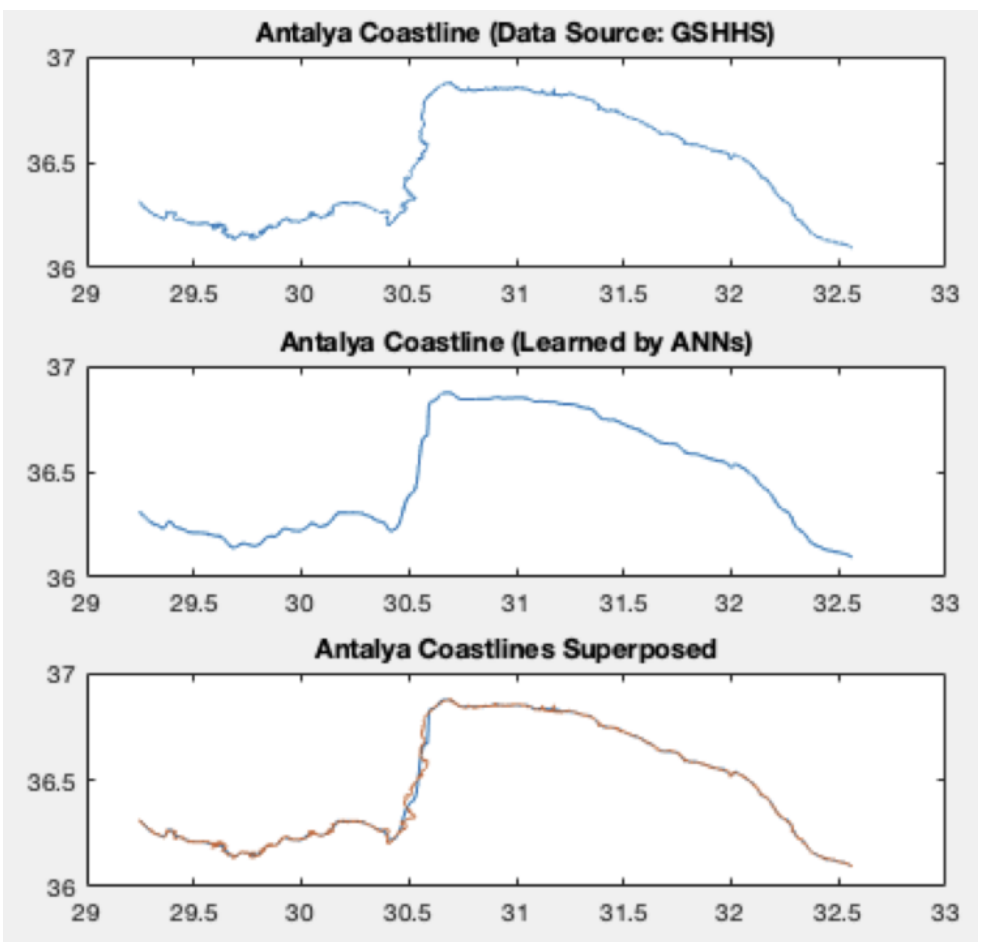


Fig. 2. Antalya's Coastline and Its Approximate Function

Artificial neural networks (ANNs) are used to get a continuous function instead of separate coordinates. Longitudes are inputs of the ANNs, and latitudes are the outputs. Supervised learning is used as one input variable and one output variable to ANNs. GSHHS data is the training data. "Fig. 3" illustrates the structure of supervised ANNs. The number of the hidden neurons is fifty, and there is a single hidden layer.

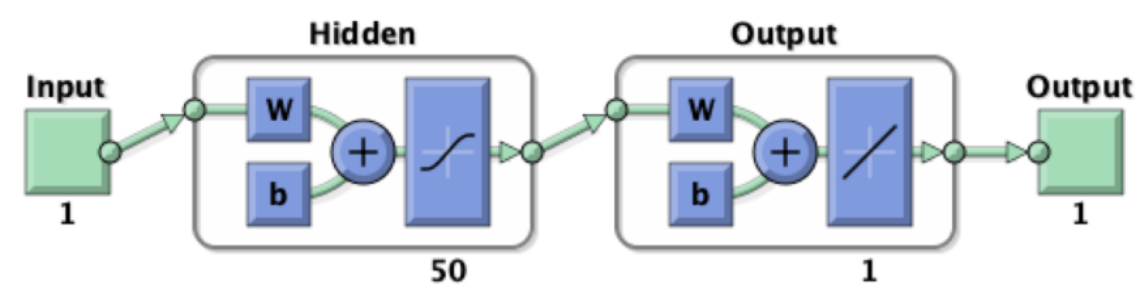

Fig. 3. Structure of the ANNs (image produced by Matlab Software)

Levenberg-Marquardt (LM) backpropagation algorithm is used as the learning algorithm of ANNs [23-27]. In the learning stage, the network's output is compared with the latitude of the training data, and ANNs adjust the weights accordingly. Training stops after reaching desired proximity. More importantly, the mean squared error of the network is $8.0848^{\circ} \mathrm{e}-04(2.9105$ seconds). It takes 182 iterations for the LM algorithm to finish the learning process. The purpose of using ANNs is to obtain a continuous function that will calculate the latitude of any longitude on Antalya's coastline. It is assumed that the facility is on the coast; therefore, a possible facility's latitude is calculated as a function of its longitude. The flowchart of the optimization problem can be seen in Fig. 4.

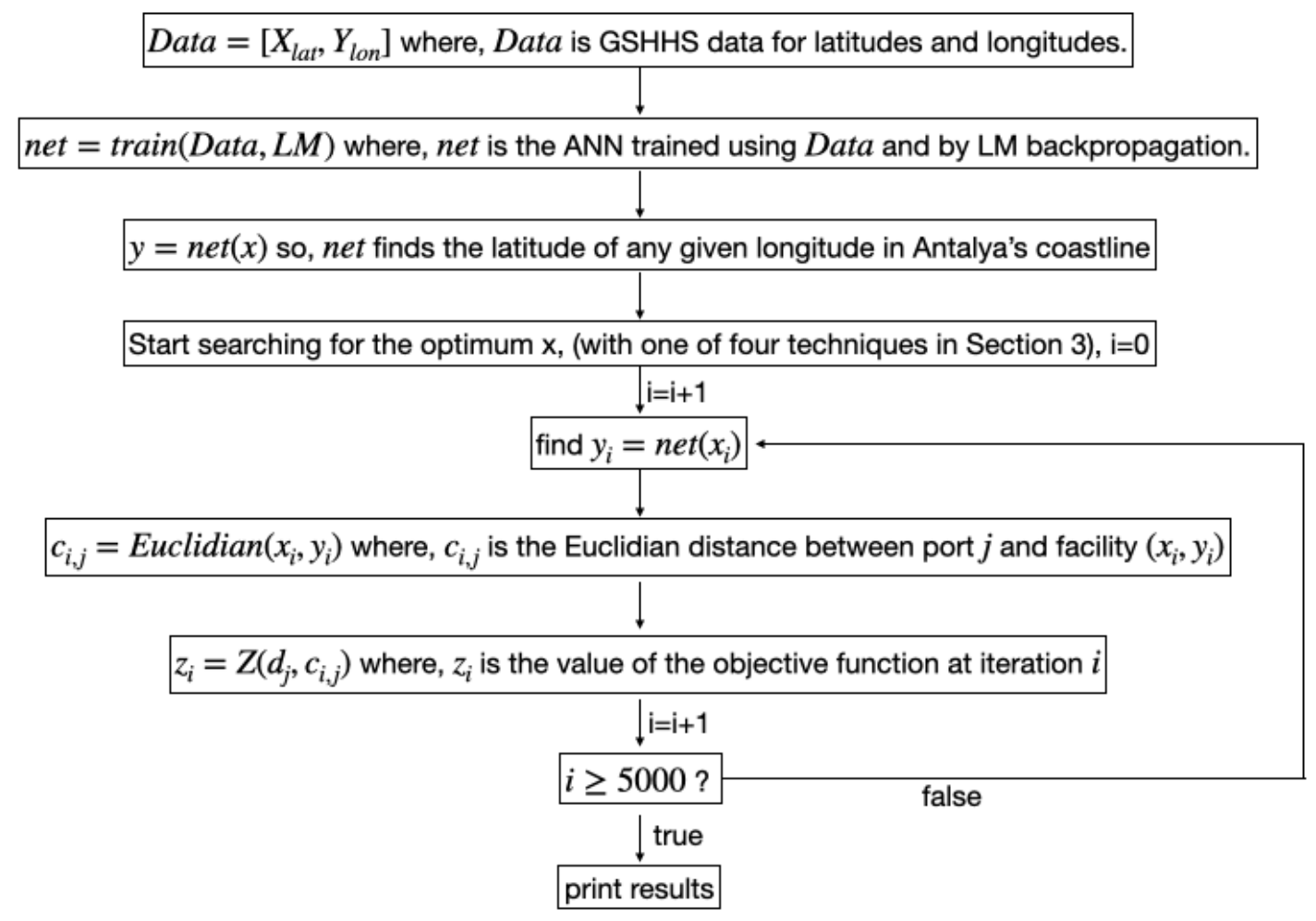

Fig. 4. Flowchart of the Optimization Problem 


\section{Methodology}

\subsection{Tree Seeds Algorithm (TSA)}

Trees reproduce through their seeds in their natural environment. Seeds can reach far distances with probabilistic effects like animals and winds. In nature, only the seeds with high survival potential can grow up. In the TSA method, which was inspired by this natural event, trees represent solution vectors and seeds represent candidate solutions. The workflow of the TSA method in this paper is as follows [12]:

\subsubsection{First step}

Search parameters are defined in the initial step. The number of trees $\left(N_{p o p}\right)$ is chosen as five. The number of seeds is assigned randomly for each three and is between one and three. In other words, the minimum number of seeds per tree $\left(\right.$ seed $\left._{\min }\right)$ is one and the maximum number of seeds per tree $\left(\right.$ seed $\left._{\max }\right)$ is three. Initial trees and initial seeds are selected randomly. Search Tendency $(S T)$ is a parameter adjusting the probabilistic spread rate of seeds and is chosen as 0.8 . The number of maximum iterations (maxiter) is chosen as five thousand and it defines the maximum number of seeds that can be produced during the optimization process.

The vector of initial solutions includes a vector of initial longitudes that may be optimal for a marine facility. In this study, latitudes are dependent on the longitudes, because of the continuous function described in Section 2. Therefore, the initial solutions are produced randomly.

\subsubsection{Second step}

In this step, seeds are produced for each tree. The number of candidate solutions $\left(N_{\text {seeds }}\right)$ is between seed $_{\min }$ and seed $d_{\max }$. Each seed is produced by the formula below:

$$
\begin{aligned}
& \text { if } \operatorname{rand}(1)<S T \text { then } S_{i, j}=T_{i}+(1-2 \cdot \operatorname{rand}(1)) \cdot\left(T_{\text {best }}-S_{i, j}\right) \\
& \text { if } \operatorname{rand}(1) \geq S T \text { then } S_{i, j}=T_{i}+(1-2 \cdot \operatorname{rand}(1)) \cdot\left(T_{i}-S_{i, j}\right) \\
& i \in 1,2, \ldots, N_{\text {pop }} ; j \in 1,2,3=N_{\text {seeds }}
\end{aligned}
$$

Where $S_{i, j}$ represents seed $j$ of tree $i, T_{i}$ is tree $i, T_{\text {best }}$ shows the best solution among the trees, rand(1) is a function producing a random number between 0 and 1. As seen in Eq. (2) each seed is produced by its tree depending on the possibility of the random integer being higher or lower than ST. Kiran argues that higher values of $S T$ lead to better local search and faster convergence, whereas lower values of $S T$ lead to better global search.

\subsubsection{Third step}

At the final step, produced seeds are compared with their belonging trees. A seed, which is better than its tree and other seeds, replaces its belonging tree. Steps 2 and 3 continue until the number of produced seeds exceeds maximum iterations.

\subsection{Symbiotic Organisms Search (SOS)}


Similar to TSA, another brand-new and keen metaheuristic optimization algorithm is SOS. This algorithm simulates the method of interaction of animals between each other [13]. The term symbiotic stands for the relationship of animals to survive in nature. Three main relationships are inspired by the SOS algorithm. These relationships are mutualism, commensalism, and parasitism. Mutualism is when both of the interacting animals benefit from the relationship. Commensalism is when one of the animals benefits while the other is neutral and parasitism is when one animal benefits while the other animal is harmed. In the current optimization problem, SOS parameters are adapted as follows:

- Organism: candidate marine facility longitude

- Ecosystem: vector of candidate solutions (organisms)

- Survival fitness: objective function (fitness is higher when the objective function is lower)

- Mutualism: changing two of the organisms in a positive manner (their fitness value will increase)

- Commensalism: selecting two candidate solutions and positively changing one candidate solution while leaving the other candidate neutral

- Parasitism: changing a candidate solution and replacing another solution with the changed one

\subsubsection{First step}

Vector of initial solutions is selected randomly just like it is done in the TSA method. Initial solutions vector $X$ consists of 5 candidates $\left(N_{\text {pop }}=5\right)$.

\subsubsection{Second step (mutualism)}

Two solutions are randomly selected from the pool and these solutions are updated as follows:

$$
\begin{aligned}
& X_{i}^{\text {new }}=X_{i}+\operatorname{rand}(1) \cdot\left(X_{\text {best }}-\operatorname{round}(1+\operatorname{rand}(1)) \cdot \frac{X_{i}+X_{j}}{2}\right) \\
& X_{j}^{\text {new }}=X_{j}+\operatorname{rand}(1) \cdot\left(X_{\text {best }}-\operatorname{round}(1+\operatorname{rand}(1)) \cdot \frac{X_{i}+X_{j}}{2}\right) \\
& i, j \in 1,2, \ldots, N_{\text {pop }}
\end{aligned}
$$

Where $X_{i}$ and $X_{j}$ represent randomly selected candidate solutions, $X_{i}^{\text {new }}$ and $X_{J}^{\text {new }}$ show updated versions of the selected solutions, $X_{\text {best }}$ is the best solution in the ecosystem. Updated solutions replace their previous versions depending on their fitness value. This phenomenon is presented in Eq. $(4,5)$.

$$
\begin{aligned}
& \text { if } Z\left(X_{i}^{\text {new }}\right)<Z\left(X_{i}\right) \text { then } X_{i}=X_{i}^{\text {new }} \\
& \text { if } Z\left(X_{j}^{\text {new }}\right)<Z\left(X_{j}\right) \text { then } X_{j}=X_{j}^{\text {new }}
\end{aligned}
$$

\subsubsection{Third step (commensalism)}

In the commensalism phase, a randomly selected organism (with index $i$ ) is updated with another randomly selected organism (with index $j$ ). This phenomenon is represented by Eq. (6).

$$
X_{i}^{\text {new }}=X_{i}+(1-2 \cdot \operatorname{rand}(1)) \cdot\left(X_{\text {best }}-X_{j}\right)
$$

The updated solution replaces its old version depending on their fitness power as indicated by Eq. (4). 


\subsubsection{Fourth step (parasitism)}

A random solution (with index $i$ ) is chosen as the parasite. The parasite replaces another randomly selected solution (with index $j$ ) depending on their fitness values. This phenomenon is presented by Eq. (7).

$$
\text { if } Z\left(X_{i}\right)<Z\left(X_{i}\right) \text { then } X_{j}=X_{i}
$$

Steps among 2 and 4 continue until maximum iterations are reached. maxiter is set to five thousand in order to get a comparison between performances of TSA, SOS, and STOA.

\subsection{Sooty Terns Optimization Algorithm (STOA)}

STOA is a bio-inspired optimization tool simulating migration and attacking behavior or sooty terns [14]. Sooty terns are seabirds and generally hunt as a group in nature. Seasonal movement of the birds to find locations with more prey is called migration and their hunting event is called attacking behavior. During migration, birds start from different initial locations to avoid collusion and travel through the fittest bird's direction. When sooty terns start attacking, they move in a spiral curve. The phenomenon described above is implemented to the current problem as follows:

- Sooty tern: candidate solution

- Group of sooty terns: vector of candidate solutions

- Fittest bird: solution with the lowest objective function value

- Migration and attacking behavior: updating the solution vector in order to reach the optimum solution

\subsubsection{Migration behavior}

$$
\overrightarrow{C_{s t}}=S_{A} \cdot \overrightarrow{P_{s t}}(i)
$$

Where, $\vec{C}_{s t}$ is the position and it should not collide with another search agent, $S_{A}$ is used to compute new search agents, $\vec{P}_{s t}(i)$ is the candidate solution $i\left(i=1,2, \ldots, N_{p o p}\right)$ in the solution vector $\vec{P}_{s t} . N_{\text {pop }}$ is taken as 5 , so the iterations start with 5 initial solutions.

$$
S_{A}=C_{f}-\left(j \cdot C_{f} / \text { Maxiter }\right)
$$

Where $C_{f}$ adjusts $S_{A}$ to avoid the collision, as $j$ is the current iteration. Eq. $(8,9)$ are here to avoid collusion, with Eq. (10) candidate solutions approach towards the best solution in the pool.

$$
\overrightarrow{M_{s t}}=0.5 \cdot \operatorname{rand}(1) \cdot\left(\overrightarrow{P_{b s t}}-\overrightarrow{P_{s t}}(i)\right)
$$

In the formula above, $\overrightarrow{M_{s t}}$ indicates different positions of the solutions, $\overrightarrow{P_{b s t}}$ is the best solution in the pool.

\subsubsection{Attacking behavior}


Sooty terns start their hunt after taking their positions, Eq. (11) shows how the vector of solutions is updated to get better solutions during the ongoing iterations.

$$
{\overrightarrow{P_{s t}}}_{\text {new }}=\left(\overrightarrow{C_{s t}}+\overrightarrow{M_{s t}}\right) \cdot \sin (\operatorname{rand}(1) \cdot 2 \cdot \pi)+{\overrightarrow{P_{s t}}}_{\text {old }}
$$

\subsection{Weiszfeld Algorithm (WA)}

In 1937, WA was first founded by a mathematician [15]. It is an old but valuable algorithm for location analysis problems. The main reason to include WA in this study is to compare the performances of TSA, SOS, and STOA with an older method like WA. The standard version of WA is adopted in this study as in Eq. (12):

$$
X_{k+1}=\frac{\sum_{j=1}^{N_{\text {ports }} \frac{w_{j} \cdot X_{k}}{d_{j}}}}{\sum_{j=1}^{N_{\text {ports }} w_{j}} \frac{w_{j}}{d_{j}}}
$$

Where, $X_{k}$ is the current value of the possible optimum longitude of the marine facility, $X_{k+1}$ is the longitude of the facility in the next iteration, $w_{j}$ is the weight (anchorage capacity) of the port $j$ and $d_{j}$ is Euclidean distance between port $j$ and the current location of the facility (note that the latitude of the facility can be calculated by the ANN as a function of its longitude as described in Section 2). Maximum iterations are set to five thousand similar to TSA and SOS methods. WA is a successful algorithm for optimizing the task in this research, however it fails to address the spatial difficulties such as mountainous terrains because it uses the great-circle distance for the application [28].

\subsection{Parameters Selection}

Metaheuristic optimization techniques are known to be dependent on parameter tuning. In the TSA method, ST is a parameter between 0 and 1. Smaller values of ST parameter lead to better global search while higher values lead to better local search. In this problem ST is taken as 0.8 . And the number of trees is $5\left(N_{p o p}=5\right)$. SOS method is not heavily dependent on the parameters selected. The number of organisms is $5\left(N_{p o p}=5\right)$. In the STOA method, $C_{f}$ parameter is used to avoid collusion between the solutions. $C_{f}$ is taken as 0.1 and the number of birds is 5 $\left(N_{\text {pop }}=5\right)$. The parmeters are presented in "Table 1". In the WA method, no parameter has been used as described in Section 3.4.

Table 1. Selected Parameters

\begin{tabular}{ccc}
\hline Method & $N_{\text {pop }}$ & Parameter \\
\hline TSA & 5 & $\mathrm{ST}=0.8$ \\
SOS & 5 & - \\
STOA & 5 & $C_{f}=0.1$ \\
\hline
\end{tabular}

\section{Results and Discussions}

The marine facility location for the emergency problem presented in Section 2 is solved by using three optimization techniques described in Section 3. All four algorithms are run five times in order to see if the initial solutions, which are randomly selected, will impact on the results. The first algorithm, namely TSA, converged to the same optimal solution in each run 
regardless of the assigned initial solution. The convergence history of the iterations in the TSA method is shown in "Fig. 5". The x-axis of the figure is drawn on the logarithmic scale because most of the change in the best candidate solution is made at the beginning of the run.

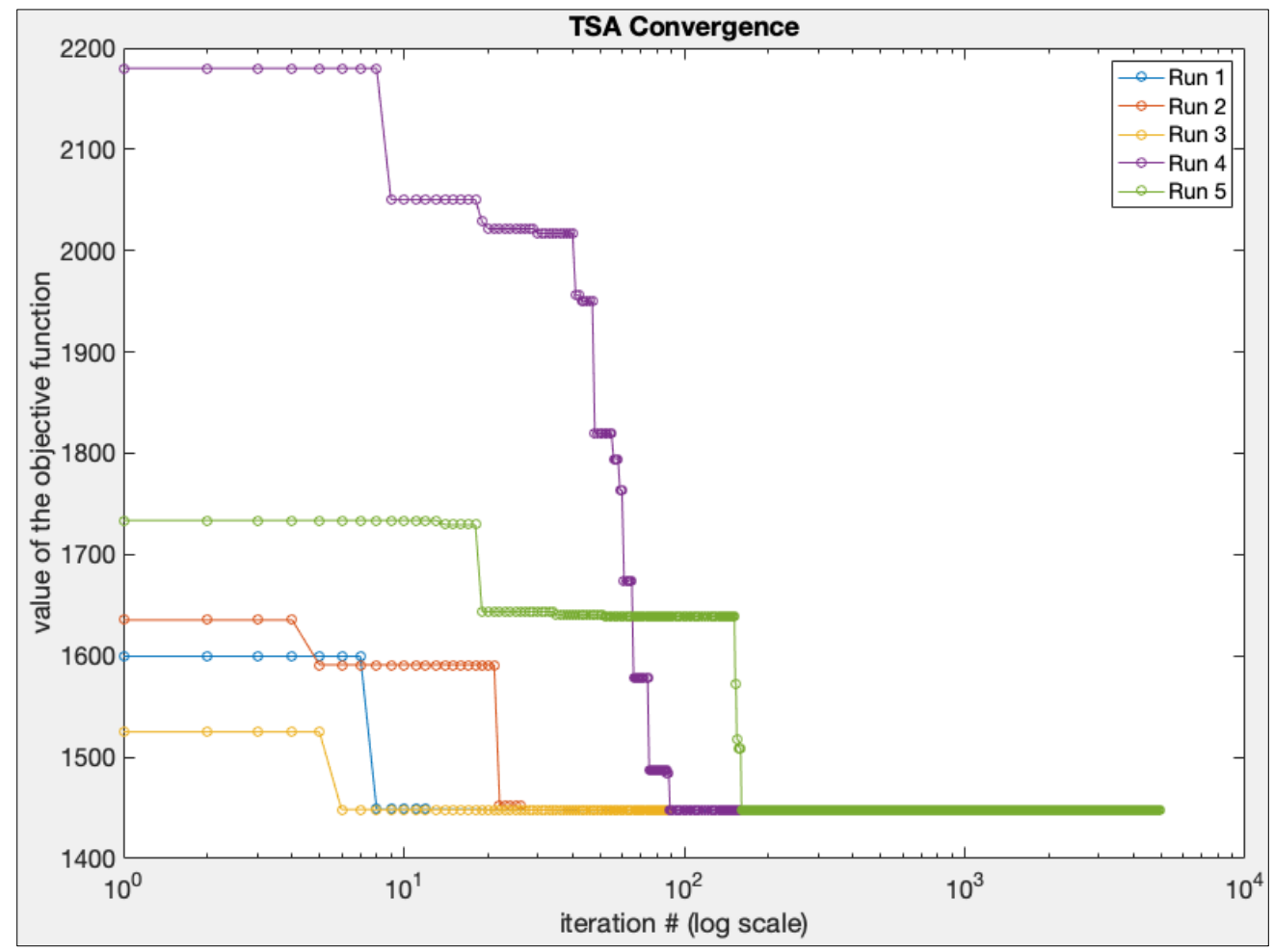

Fig. 5. Convergence of TSA Method

SOS algorithm converges to the same point regardless of the initial solutions. However, the coordinates found by SOS are different from the coordinates found by TSA and STOA methods. The convergence of the SOS algorithm is shown in "Fig. 6", below. 


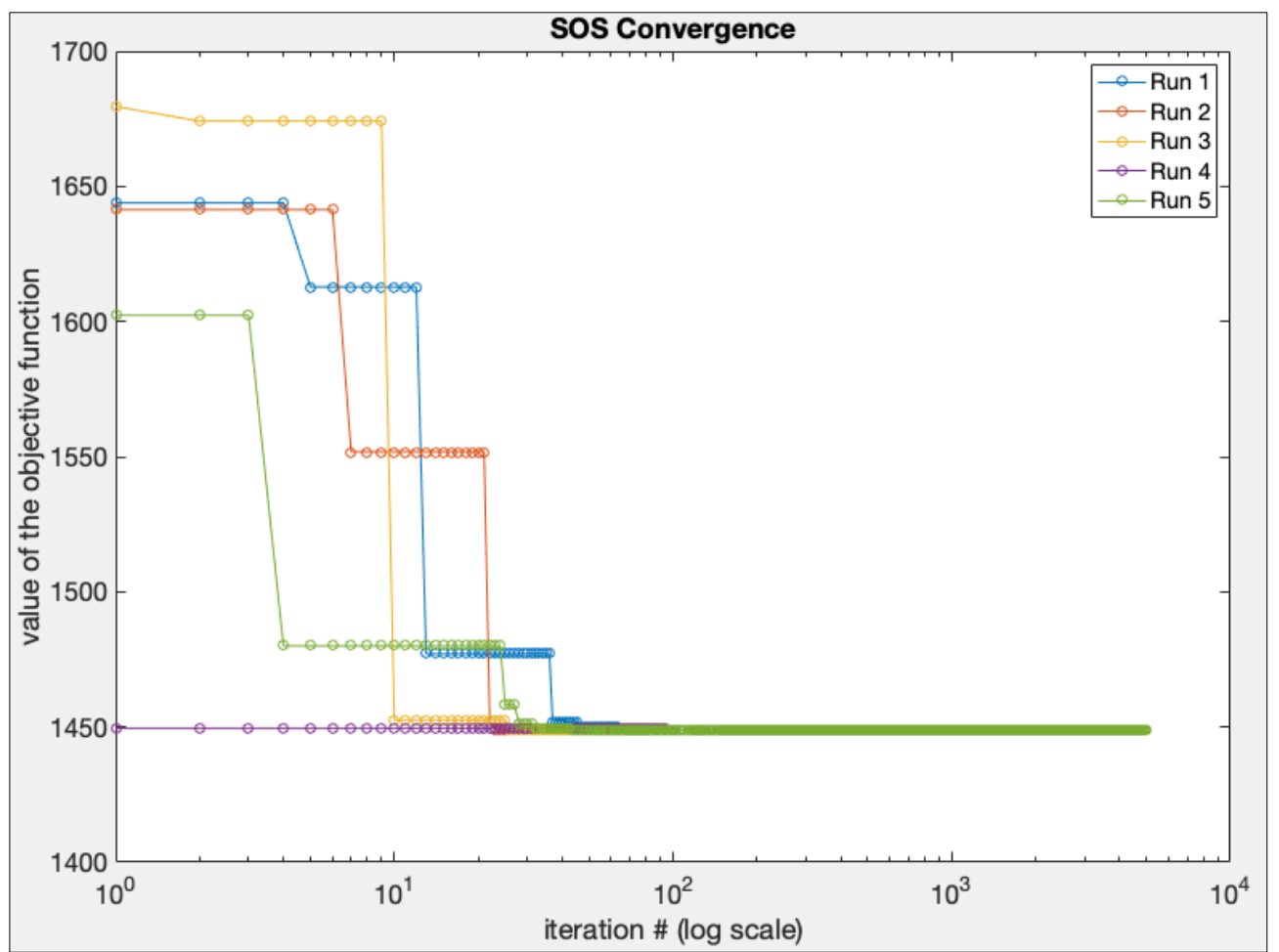

Fig. 6. Convergence of SOS Algorithm

STOA found a slightly different coordinate from the coordinate found by TSA. However, these two techniques produced similar results. Like the other four algorithms, STOA converges to the same coordinate at each of the five runs.

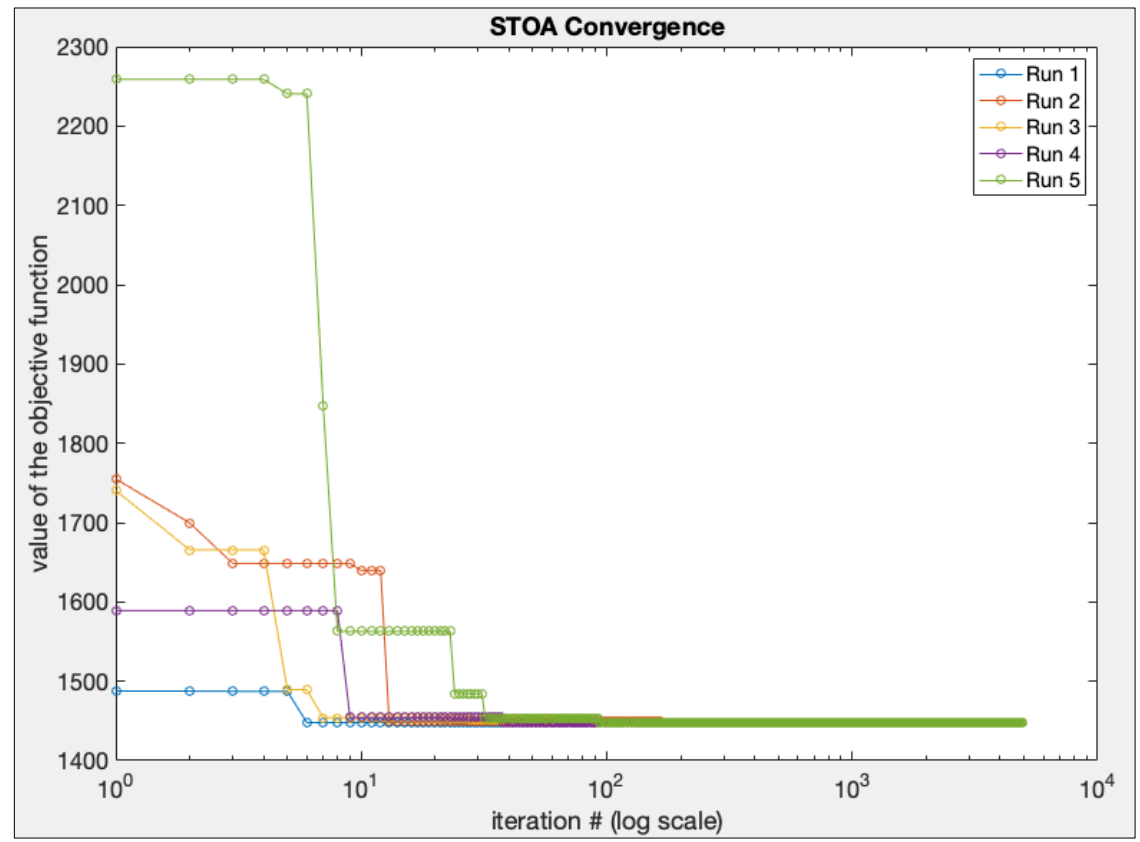

Fig.7. Convergence of STOA Method

WA seems to have lower performance in this problem because the value of the objective function is higher than the first two algorithms. The converged coordinate in WA is the same regardless of the initial solutions assigned. WA convergence is shown in "Fig. 8". In WA, the coded algorithm replaces $x_{i-1}$ value with $x_{i}$, even if the $z_{i}$ is higher than $z_{i-1}$ (where, $x_{i}$ is the longitude of the facility and $z_{i}$ is the corresponding value of the objective function at iteration 
i). Thus, fluctuations occur in the search history, as shown in "Fig 8.". The location found by WA, shown in "Fig 9.d", is the coordinates at the iteration with the lowest $z$ in the search history.

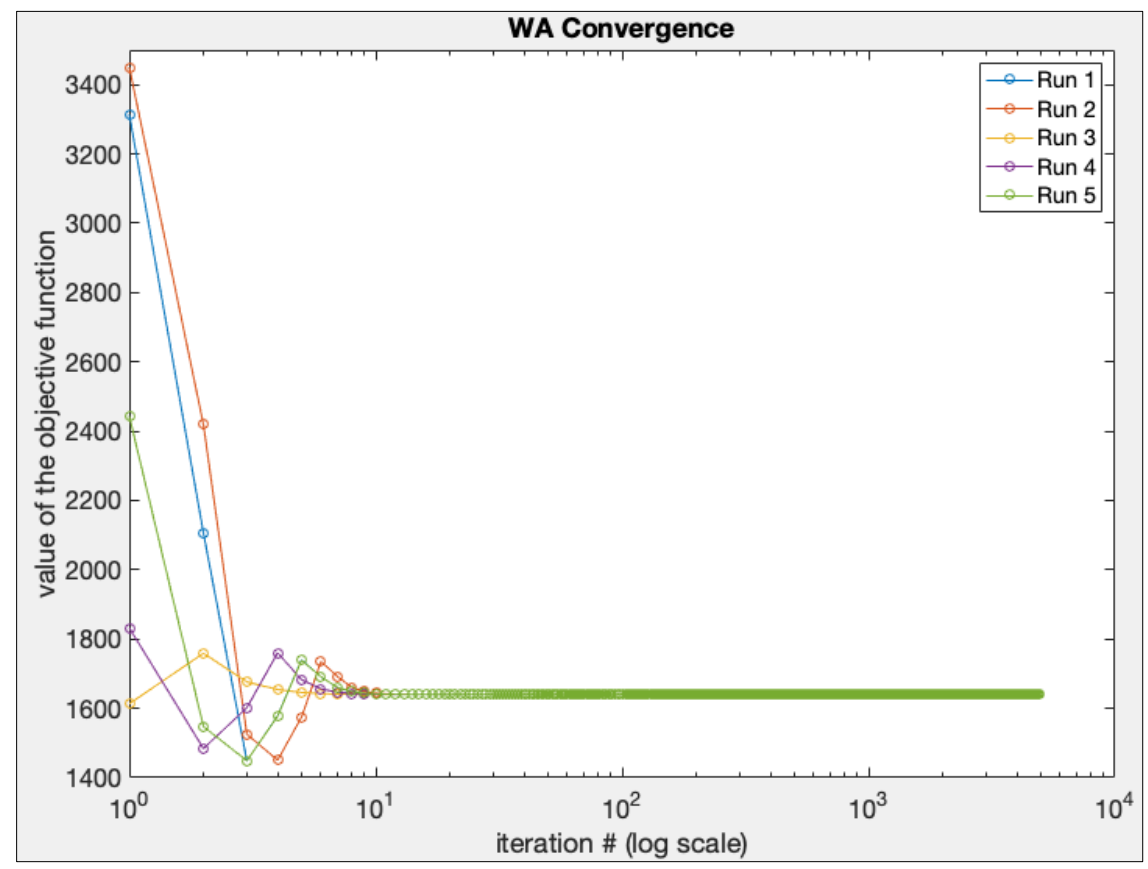

Fig. 8. Convergence of WA Method

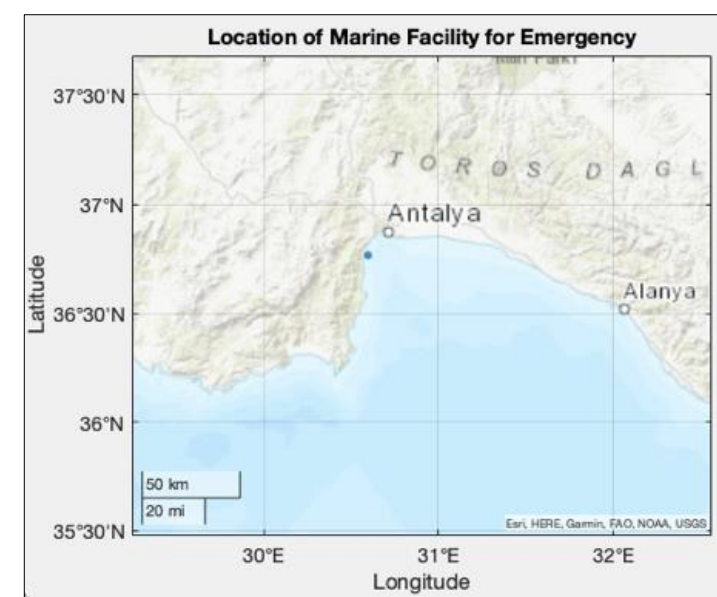

a) Optimum Location by TSA

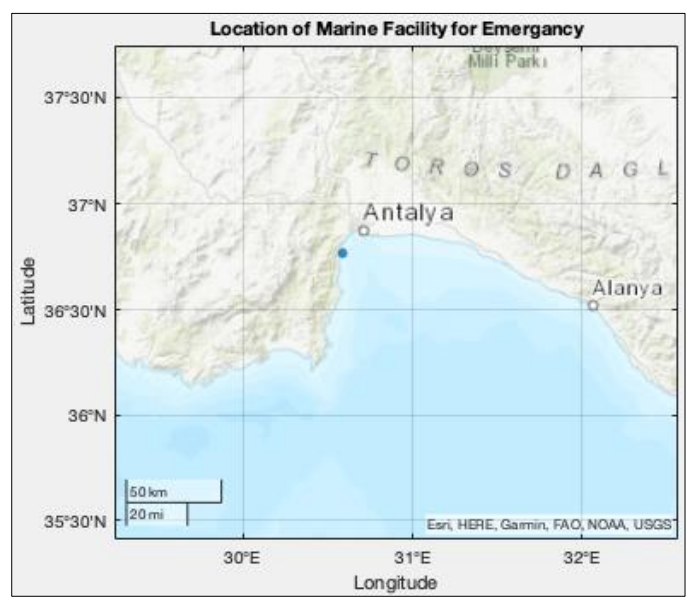

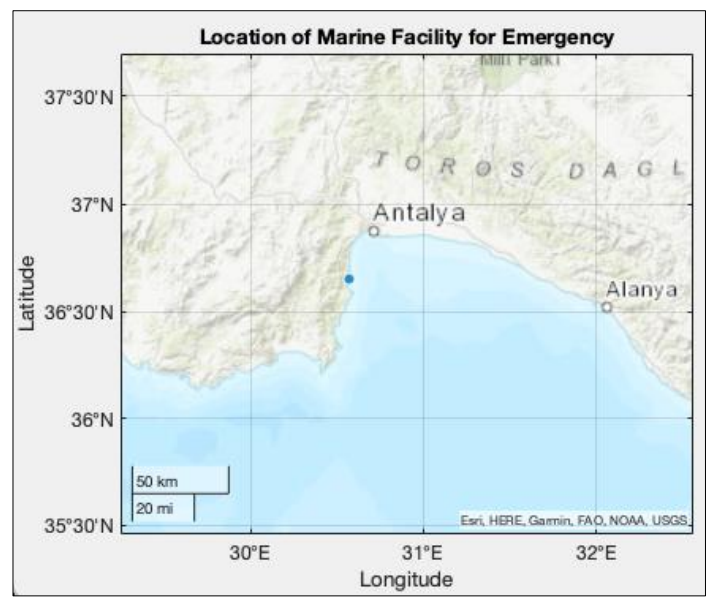

b) Optimum Location by SOS

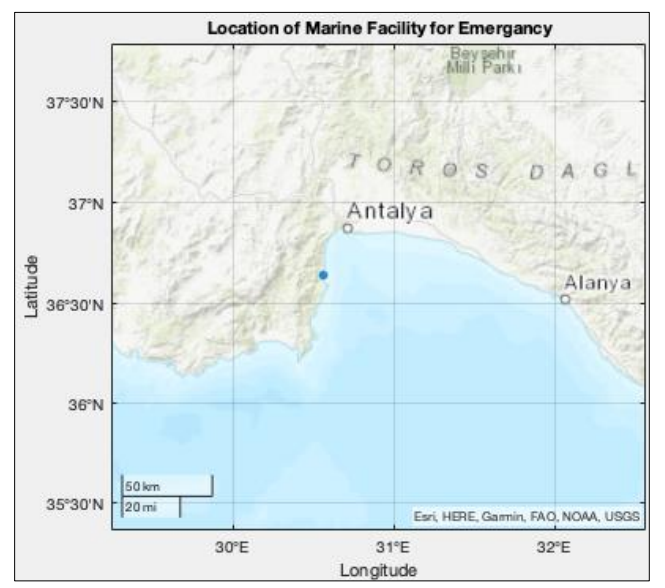



c) Optimum Location by STOA
d) Optimum Location by WA

Fig. 8. Optimum Location of Single Marine Facility for Emergency

Table 2. Coordinates of the Marine Facility for Emergency

\begin{tabular}{cccc}
\hline Method & Latitude & Longitude & Objective Value \\
\hline TSA & $36.7689^{\circ}$ & $30.5914^{\circ}$ & 1447.1 \\
SOS & $36.6559^{\circ}$ & $30.5689^{\circ}$ & 1448.9 \\
STOA & $36.7686^{\circ}$ & $30.5914^{\circ}$ & 1447.2 \\
WA & $36.6443^{\circ}$ & $30.5622^{\circ}$ & 1448.4 \\
\hline
\end{tabular}

Table 2 presents the optimum locations found by four algorithms and the respective values of the objective functions. Please note that lower values of the objective function are desired. It is seen that TSA gives the best location among the four methods. TSA reached an objective function value of 1447.1, SOS reached an objective function value of 1448.9, STOA's objective function was 1447.2 in value and WA reached an objective function value of 1448.4. The location found by TSA $\left(36.7689^{\circ} \mathrm{N}, 30.5914^{\circ} \mathrm{E}\right)$, which can be shown in "Fig. 7", seems to be more optimal. STOA's location $\left(36.7686^{\circ} \mathrm{N}, 30.5914^{\circ} \mathrm{E}\right)$ is very close to TSA with a slight difference in latitudes and it can be considered inside of the error margin of the continuous function driven by ANN. The location that is found by $\operatorname{SOS}\left(36.6559^{\circ} \mathrm{N}, 30.5689^{\circ} \mathrm{E}\right)$ is near the location found by TSA. The difference in the latitudes between these two points is $0.0225^{\circ}$ which is higher than the mean squared error of the continuous function of the coastline $\left(8.0848^{\circ} \mathrm{e}-04\right)$, so the difference between TSA and SOS performances is meaningful. Therefore, performances of TSA and SOS are similar, yet TSA has slightly better performance for this problem.

WA proposed a location on the western side of the region with a higher objective value, thus WA has a lower performance. In addition, the location sits on a concave-shaped coast which signs that the algorithm is trapped at a local minimum. In WA type of optimization algorithms, the shape of the function does matter in reaching the global minimum/maximum. The interesting part of the WA result is that the algorithm proposes the same location regardless of the initial location it started from, similar to the other two algorithms.

\section{Conclusions and Further Study}

Human life is endangered when accidents or disasters occur at sea. When a leak occurs in Turkey's Antalya Gulf, it is critical to limit the damage, thus the mediation should happen as soon as possible. If the intervention is made quickly, the accident's consequence may be less severe, and vice versa. To summarize the significant point of this article, an appropriate location for a counter spillage group office for Antalya's ports is desired, as no area has been designated for this intent lately.

Moreover, the following is a description of the paper's uniqueness and the main contribution to the literature. To begin, four optimization strategies, TSA, SOS, STOA, and WA were used in this study to determine the best placement for an emergency response center. In addition, several other transportation engineering challenges were tackled using these four approaches. However, for the first time in this study, the presentations of the four optimization techniques were studied and scrutinized simultaneously. Later, their performances were compared and discussed. Second, the ideal locations for a counter spillage group office were selected for the 
first time in the literature for Antalya's ports. In addition, this study evaluated and discussed the suggested location and its spatial characteristics.

As a result, the brand-new techniques TSA, SOS, and STOA seem to perform well for this problem. However, the standard version of WA provided a similar solution to other techniques applied in this study. Moreover, TSA and STOA determined the same location for the crisis reaction office area, while SOS and WA suggested slightly different locations. Furthermore, TSA produced the best performance among all methods performed in the article.

A similar study may be done on different regions in a country or the world. The performances of the algorithms may be different on different coastlines. The results of these studies may be compared with the actual locations of the emergency facilities or may give an idea of location determination for facilities yet to be placed. Further studies may also be done using up-to-date coastal navigation techniques instead of Euclidean distance to determine the distance between a crisis reaction office area and a port. Logically, the use of navigation techniques may have an impact on the result. Another way for a further study would be using statistical data in determining the possibility of an accident at a given port. In this study, it is assumed that this possibility is proportional to ports' capacity. The use of statistical data may lead to more specific results.

\section{References}

[1] Atherton, T., Wilks, J., Health and safety in Australian marine tourism: A social, medical and legal appraisal. Journal of Tourism Studies, 5(2), 2-16, 1994.

[2] Bentley, T., Page, S., Meyer, D., Chalmers, D., Laird, I., How safe is adventure tourism in New Zealand? An exploratory analysis. Applied ergonomics, 32(4), 327-338, 2001.

[3] Yang, E.C.L., Sharif, S.P., Khoo-Lattimore, C., Tourists' risk perception of risky destinations: The case of Sabah's eastern coast. Tourism and Hospitality Research, 15(3), 206-221, 2015.

[4] Carpenter, S.R., Stanley, E.H., Vander Zanden, M.J., State of the world's freshwater ecosystems: physical, chemical, and biological changes. Annual review of Environment and Resources, 36, 75-99, 2011.

[5] Barbier, E.B., Burgess, J.C., Folke, C., Paradise Lost?: the ecological economics of biodiversity (Vol. 2), Routledge, 2019.

[6] Ficke, A.D., Myrick, C.A., Hansen, L.J., Potential impacts of global climate change on freshwater fisheries. Reviews in Fish Biology and Fisheries, 17(4), 581-613, 2007.

[7] Lafferty, K.D., Harvell, C.D., Conrad, J.M., Friedman, C.S., Kent, M.L., Kuris, A.M., ... Saksida, S.M., Infectious diseases affect marine fisheries and aquaculture economics. Annual review of marine science, 7, 471-496, 2015.

[8] Akis, A., The effects of mass tourism: A case study from Manavgat (AntalyaTurkey). Procedia-Social and Behavioral Sciences, 19, 289-296, 2011.

[9] Ozdemir, B., Aksu, A., Ehtiyar, R., Çizel, B., Çizel, R.B., İçigen, E.T., Relationships among tourist profile, satisfaction and destination loyalty: Examining empirical evidences in Antalya region of Turkey. Journal of Hospitality Marketing \& Management, 21(5), 506540, 2012. 
[10] de Meo, I., Miglietta, C., Mutlu, E., Deval, M.C., Balaban, C., Olguner, M.T., Ecological distribution of demersal fish species in space and time on the shelf of Antalya Gulf, Turkey. Marine Biodiversity, 48(4), 2105-2118, 2018.

[11] Gul, M., Ak, M.F., A comparative outline for quantifying risk ratings in occupational health and safety risk assessment. Journal of Cleaner Production, 196, 653-664, 2018.

[12] Kiran, M.S., TSA: Tree-seed algorithm for continuous optimization. Expert Systems with Applications, 42(19), 6686-6698, 2015.

[13] Cheng, M.Y., Prayogo, D., Symbiotic organisms search: a new metaheuristic optimization algorithm. Computers \& Structures, 139, 98-112, 2014.

[14] Dhiman, G., Kaur, A., STOA: a bio-inspired based optimization algorithm for industrial engineering problems. Engineering Applications of Artificial Intelligence, 82, 148-174, 2019.

[15] Weiszfeld, E., Sur le point pour lequel la somme des distances de n points donnés est minimum. Tohoku Mathematical Journal, First Series, 43, 355-386, 1937.

[16] Aydoğdu, İ., Comparison of metaheuristics on multi objective (cost\&C0 2) optimization of RC cantilever retaining walls. Pamukkale University Journal of Engineering Sciences, 23, 2017.

[17] Demir, E., Havalimanlarında kalkış öncesi, acil durumlarda, yardım alınabilecek en uygun lokasyonun Weber problemine uyarlanarak belirlenmesi. Türk Coğrafya Dergisi, 70, 81$85,2018$.

[18] Demir, E., Kockal, N.U., Iterative methodology on locating a cement plant. Journal of Inequalities and Applications, 2019, 1-8, 2019.

[19] Uzun, B., Civalek, O., Aydogdu, I., Optimum design of nano-scaled beam using the social spider optimization (SSO) algorithm. Journal of Applied and Computational Mechanics, 2019.

[20] Demir, E., Aydoğdu, İ., Transportation Path Assignment Within the Airports in Turkey. In International Conference on Harmony Search Algorithm, Springer, Singapore, pp 207217,2020

[21] Demir, E., Trafik Verilerine Göre Afetlerde Bölgesel Hizmet Verebilecek İdeal Havalimanı Önerileri. Doğal Afetler ve Çevre Dergisi, 7, 101-109, 2021.

[22] Wessel, P. and Smith, W. H., A global, self-consistent, hierarchical, high-resolution shoreline database. Journal of Geophysical Research: Solid Earth, 101(B4), 8741-8743, 1996.

[23] Moré, J.J., The Levenberg-Marquardt algorithm: implementation and theory. In Numerical analysis (pp. 105-116). Springer, Berlin, 1978.

[24] Ranganathan, A., The levenberg-marquardt algorithm. Tutoral on LM algorithm, 11(1), 101-110, 2004.

[25] Marquardt, D., An Algorithm for Least-Squares Estimation of Nonlinear Parameters, SIAM Journal on Applied Mathematics, 2, 431-441, 1963. 
[26] Hagan, M.T., Menhaj, M.B., Training feedforward networks with the Marquardt algorithm. IEEE transactions on Neural Networks, 5(6), 989-993, 1994.

[27] Hagan, M.T., Demuth, H.B., Beale, M.H., Neural Network Design, PWS Publishing, 1996.

[28] King, T., Soltys, M., Minimum Path Star Topology Algorithms for Weighted Regions and Obstacles. arXiv preprint arXiv:2109.06944, 2021. 